\title{
Digital citizenship trend in educational sphere: A systematic review
}

\author{
Wibowo Heru Prasetiyo ${ }^{1}$, Noor Banu Mahadir Naidu ${ }^{2}$, Bee Piang Tan ${ }^{3}$, Bambang Sumardjoko ${ }^{4}$ \\ ${ }^{1,4}$ Department of Civic Education, Faculty of Teacher Training and Education, Universitas Muhammadiyah Surakarta, \\ Surakarta, Indonesia \\ ${ }^{2,3}$ Department of Social Studies and Citizenship, Faculty of Human Sciences, Sultan Idris Education University, Malaysia
}

\begin{tabular}{l} 
Article Info \\
\hline Article history: \\
Received Feb 19, 2021 \\
Revised Aug 13, 2021 \\
Accepted Sep 10, 2021 \\
\hline
\end{tabular}

\section{Keywords:}

Digital citizenship

Digital competence

Digital literacy

ICT skills

\begin{abstract}
The surge of information in the digital age has impacted social problems. Accordingly, digital citizenship had been discussed mostly within topics related to digital security, IT education. A systematic review is needed to provide an overview for educators and policymakers in Indonesia to address ethical and technical issues to improve the online environment safely. However, there are limited studies that systematically review the existing literature on implementing digital citizenship in Indonesia. The present study was guided by PRISMA review protocol using three databases, i.e., Scopus, Google Scholars, and ProQuest, concerned with digital citizenship, digital competence, digital literacy, and information and communications technology (ICT) skills. There were 205 articles screened; this study obtained 20 articles that fit the predetermined inclusion criteria. This study used content analysis to encode, organize categories, and develop the themes. Based on the thematic analysis, this study has three main themes namely digital readiness, digital citizenship competencies, and educational policies. This review contributes to the existing literature by providing direction to future study and embedded digital citizenship competencies in the educational setting as a catalyst for a new literacy.
\end{abstract}

This is an open access article under the $\underline{C C B Y-S A}$ license.

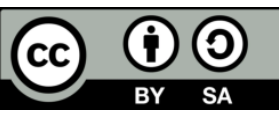

\section{Corresponding Author:}

Wibowo Heru Prasetiyo

Department of Civic Education, Faculty of Teacher Training and Education

Universitas Muhammadiyah Surakarta

Surakarta, Indonesia

Email:whp823@ums.ac.id

\section{INTRODUCTION}

Over a few decades, the expansion of the internet in Indonesia has rapidly increased. In early 2019, from 264.16 million Indonesians, more than 171.17 million people used the internet to support their daily activities [1]. With its vast area and population, Indonesia has a large digital community that struggles to provide digital equality for all. For instance, people in urban areas tend to obtain high-speed internet access compared to residents in rural areas. The digital divide phenomenon was striking between the West and the East. Western regions such as Java, Sumatra, and Borneo dominate with $83.6 \%$ of internet use while the Eastern region was only $16.4 \%$ [1].

Indonesia has struggled with some threats of technology use, such as cybersecurity [2], [3], pornography [4], plagiarism [5], [6], and cyberbullying [7]-[9]. The government provides regulation to protect digital security namely Law Number 11/2008 on Information and Electronic Transaction (UU ITE). UU ITE aims to supervise online activities and combat cybercrime, such as hacking, malware, and fraud transactions. 
Furthermore, a cybersecurity agency was established to improve internet security [10]. Nonetheless, criticism of this rule has been widely addressed because it can be used to limit free speech [11], [12].

Literature pays attention regarding the integration of educational technology in vary. It is widely known that the internet promotes education beyond geographical and time boundaries [13], [14]. As integrating technology in education, learning culture has shifted from face-to-face to virtual learning. Within the digital environment, students join in an online course to receive materials, present their tasks, or do an exam without leaving their house. Moreover, the internet is beneficial to simplify school administration and to provide ease of school interaction with parents to supervise students [15], [16]. Nevertheless, it is essential to understand that although technology brings advantages within educational practices, it is easy to see misuse and abuse of technology in a school setting due to the lack of awareness and education regarding technology use.

The digital citizenship concept has emerged during the last few decades from experts who have sought to create a framework for the effective use of technology [17]-[20]. One of the interminable discussions is the relationship between technological competence and citizenship characteristics [21]. Digital citizenship is considered the ability to uncover information and interact with people digitally, which requires the skills to evaluate information and realize the consequences in a responsible manner. Moreover, digital citizenship focuses on utilizing digital tools to build civic engagement and solve physical or virtual problems. The most important thing is how to be an informed citizen who knows the priority between online and offline life [22]. Digital citizenship can be interpreted as a set of abilities needed by someone to conduct activities in the context of the digital environment appropriately and maintain a balance between the lives both online and offline.

Scholars predict that global society will continue to change because of technological penetration in society [23]-[26]. The learning community must provide guidance and strategies for students, teachers, and parents on how to respond and solve problems caused by the presence of technology [20]. Among the previous study, it is pointed out its role in the optimization of guidance related to responsibly using technology. Due to some reasons such as rapid utilization of technology to fulfill individual's need and rights, especially in the educational setting, it is necessary to conduct a review to allow suggesting directions in ensuring appropriate behaviors with contemporary digital tools. However, there is a limited study that systematically reviews the existing literature on implementing digital citizenship in Indonesia. Accordingly, this study chose a systematic literature review because it offers a detailed analysis of the existing research that replicable and transparent process as well as to improve the body of knowledge of digital citizenship in developing countries context. This study aims to identify research gaps to convey an understanding and contribute to the discourse on digital citizenship practice in the educational sphere. By preparing a systematic review, the result will help teachers, educational principals, researchers, and policymakers to prepare appropriate strategies in integrating digital citizenship in the curriculum.

Generally, the current study aims to explore digital citizenship discourse in Indonesia. The result is expected to provide a theoretical stance that helps teachers, school principals, parents, policymakers, and other stakeholders address them in educational settings. The study is driven by the main question: How does the current literature inform us of digital citizenship in Indonesia? Specific research questions emerged: i) What are the main dimensions of digital citizenship that mostly mentioned?; and ii) What are the main challenges of the development of digital citizenship in Indonesia?

\section{RESEARCH METHOD}

This study employed preferred reporting items for the systematic review and meta-analysis (PRISMA) approach [27]. Initially, PRISMA was developed for clinicians but it was widely adopted in various research fields, especially for evaluation studies and interventions [28], [29]. A systematic review had different characteristics compared to a meta-analysis. In a systematic review, a study was guided by formulated questions "to identify, select, and critically appraise relevant research, and to collect and analyze data from the studies that are included in the review" without a statistical approach [29]. Furthermore, this review focused on research trends in digital citizenship in Indonesia. Studies on technological settings that did not relate to the issue - the use of digital technology responsibly - were not considered.

\subsection{Data sources}

Several databases are familiar to scholars in Indonesia, i.e., Scopus, Google Scholars, and ProQuest. Digital citizenship was often interchangeably used with other terms, such as digital literacy and digital competence, in particular, to describe the ability of digital technology use. This study determined search keywords using these terms; digital citizenship, digital literacy, digital competence, and ICT skills. Therefore, this study used these keywords in each of the databases following Boolean search action as: 
(TITLE-ABS-KEY ("digital citizenship") OR TITLE-ABS-KEY ("digital literacy*") OR TITLE-ABS-KEY ("digital competence*") OR TITLE-ABS-KEY ("ICT skill*") AND TITLE-ABS-KEY ("Indonesia") AND DOCTYPE (ar) AND PUBYEAR > 2015

This study found scientific resources abundantly. Thus, determining the appropriate keywords was imperative. Each database had a feature that facilitates the search process. This study used the "advanced search" to filter findings based on predefined inclusion criteria.

\subsection{Inclusion and exclusion criteria for selection of publications}

This study limited the criteria in the databases to determine that all included articles were appropriate to answer the research question "What does reference tell us about digital citizenship in Indonesia?" This study employed the following restrictions:

i) Published between January 1, 2015, and December 30, 2020. The selection of this date range was based on the findings of empirical research on digital citizenship that began to be widely conducted after 2015 .

ii) Focused on technology usage behavior

iii) Published in an academic journal or conference paper

iv) Peer-reviewed

v) The research site was located in Indonesia

There were some reasons for applying the limitations of the criteria. First, although the concept of digital citizenship is a new issue in Indonesia, articles containing discussions about digital citizens, including digital skills and preparation for the use of ICT, were found in numerous databases. Second, Indonesian researchers tend to publish in conference papers compared to an academic journal. Third, digital citizenship studies in Indonesia may be a part of studies in a full disciplinary field.

\subsection{Screening and eligibility assessment for data analysis}

This study conducted several stages based on the inclusion criteria. Firstly, all articles that fitted with the criteria were screened. Secondly, the abstracts of the article section were screened to ensure relevance to the research objectives. Thirdly, this study conducted an in-depth reading of the full text of each article. Table 1 shows the articles that exactly fitted the criteria were grouped following some codes: database, type of document, language for publishing, study field, method, and year of publication. This study developed the thematic code for the articles after they were confirmed to the criteria mentioned. The review process was continued by conducting a content analysis consisting of major findings [30]. This stage aimed to provide an overview of general discourses about digital citizenship. Finally, this study elaborated on the findings to answer research questions in line with highlighting the scope of digital citizenship in Indonesia.

Table 1. Characteristics of included studies $(\mathrm{N}=20)$

\begin{tabular}{lc}
\hline Characteristics & Number of articles \\
\hline Database & \\
Google Scholar & 11 \\
Scopus & 8 \\
ProQuest & 1 \\
Type & \\
Journal article & 15 \\
$\quad$ Conference paper & 5 \\
Language & \\
English & 7 \\
Indonesian & 13 \\
Study Field & \\
Education & 13 \\
Computer sciences & 3 \\
Social politics & 4 \\
Methods* & \\
Interview & 9 \\
Document analysis & 8 \\
Survey & 9 \\
Observation & 3 \\
Year of publication & \\
2015 & 2 \\
2016 & 2 \\
2017 & 0 \\
2018 & 9 \\
2019 & 4 \\
2020 & 3 \\
\hline *Some research used more than one method
\end{tabular}

Int J Eval \& Res Educ, Vol. 10, No. 4, December 2021: 1192 - 1201 


\subsection{PRISMA flow diagram}

The use of appropriate protocols is essential to maintain accountability, trustworthiness, and transparency in determining what was done, discovered, and reported [27], [29]. PRISMA flow diagram contains a checklist that assists researchers to ensure each of the stages following the guidelines. Moreover, it is beneficial for reducing selection and conclusion bias. As mentioned earlier, the flow of managing information consists of screening and inclusion of various documents found. Figure 1 shows that this study obtained 205 articles consisting of journals and conference papers in largely study fields such as education, social politics, and computer sciences. Out of these, 83 articles were published in more than one database so that 122 articles were screened. This study's researchers read the title and abstract then found 78 articles did not fit the inclusion criteria. Therefore, only 44 articles qualified for the full-text screening process. As a result, this study examined 20 articles using content analysis based on some reasons: i) Has a context regarding the problem of technology use; ii) Contains elements of digital citizenship; iii) Is the latest publication from each author; iv) Is a peer-reviewed article. Then, the quality appraisal based on the article's quality was conducted as suggested by Petticrew and Roberts [31]. All articles were assessed by two experts to categorize them into three groups, namely high, moderate, and low. This process had categorized eight articles as high and 12 articles as moderate. Accordingly, 20 articles should be reviewed.

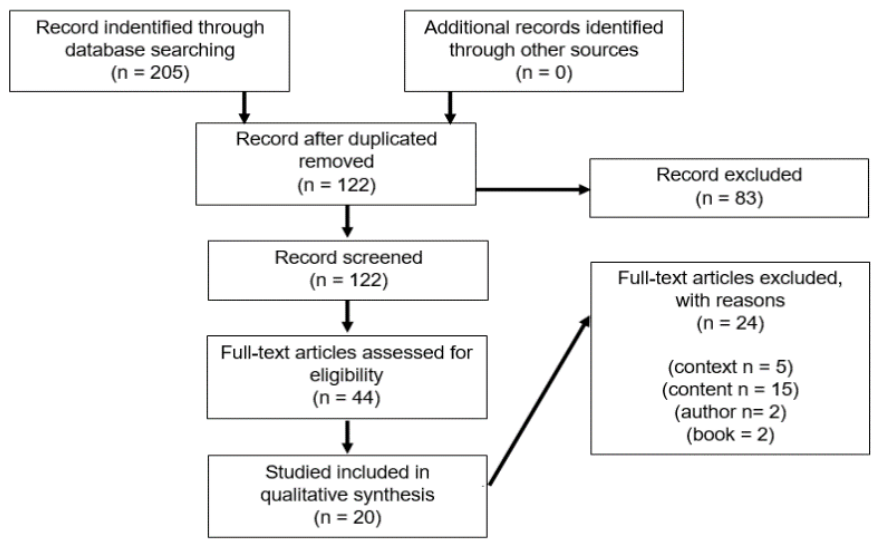

Figure 1. PRISMA flow diagram for systematic review

\section{RESULTS AND DISCUSSION}

This study employed qualitative content analysis to construct a general picture of digital citizenship discourse in Indonesia. It was started to reveal the main concept in each article. One article might have more than one main concept and there is no limit to the number of articles for each concept that appears. Each main concept reflects the dimensions that are the focus of the development of digital citizenship. Table 2 shows that there are eleven dimensions of digital citizenship: digital literacy, digital ethics, digital access, digital immigrant, digital native, digital participation, digital competence, digital commerce, online safety, ICT skill, and ICT awareness. From the result, digital literacy is mostly discussed (nine articles), followed by digital ethics (four articles), and ICT skill (four articles). Such literacies close to new literacy and skills for 21 stcentury learning promoted by educational institutions and researchers. Organisation for Economic Cooperation and Development (OECD) constitutes three dimensions, namely: information, communication, and ethics and social as competency needs in the 21 st-century [32], while Chu, et al. illustrate ten skills comprised on four categories, including ways of thinking, ways of working, tools for working, and living in the world [33]. The Partnership for 21 Century Skills (P21) conceptualizes a framework that illustrates the skills and knowledge students need to achieve success in work and life in the 21 st-century. Also, this framework is expected to provide support for the construction of 21 st-century learning outcomes [34]. The framework is divided into three categories. First, students need learning and innovation skills, which consist of critical thinking and problem solving, creativity and innovation, communication, and collaboration [35]. The three categories are well-known as 4Cs, including critical thinking, communication, collaboration, and creativity [36].

Through thematic analysis, the similar categories found in several articles are grouped to develop themes. The development of these themes helps construct a general picture of digital citizenship trends in Indonesia. The results of the analysis emerged three major themes: digital readiness, digital citizenship competence, civic education. Table 3 illustrates the distribution of included articles in each theme. 
Table 2. The main concept of digital citizenship in Indonesia

\begin{tabular}{cc}
\hline Main concept & Number of articles \\
\hline Digital literacy & 9 \\
Digital ethics & 4 \\
Digital access & 3 \\
Digital immigrant & 3 \\
Digital native & 2 \\
Digital participation & 3 \\
Digital competence & 3 \\
Digital commerce & 3 \\
Online safety & 3 \\
ICT skill & 4 \\
ICT awareness & 1 \\
\hline
\end{tabular}

Note: Some studies have more than one key concept

Table 3. Distribution of included articles in each theme

\begin{tabular}{cc}
\hline Theme & Number of articles \\
\hline Digital readiness & 11 \\
Digital citizenship competence & 15 \\
Educational policies & 3 \\
\hline Note: All themes emerged in more than one study
\end{tabular}

\subsection{Digital readiness}

Unfortunately, a rapid wave of information is not followed by a willingness to provide an appropriate response. One of the reasons, Gayatri, et al. [37] mentioned that there is inequality of technological access in Indonesia, dominated by urban compared to remote areas. Unpreparedness was also influenced by alternations between two consecutive generations that have grown up in different technological eras. Therefore, studies underlined that the use of technology had less impact on productivity. On the contrary, the findings of some studies illustrated the existence of irresponsible behavior patterns.

Initially, some researchers focused on patterns of internet use in Indonesia, such as digital owned devices and the length of internet use [38]-[40]. Furthermore, researchers investigated various improper uses of technology. Rahmawati, et al. [41] found the phenomenon of spreading fake news, well-known as hoaxes, which is distributed on social media massively. Sari, Rejekiningsih, Muchtarom [42], and Benazria [43] conducted studies about using the internet and social media. They found that users, including adolescents, had been trapped in disinformation, cyberbullying, and pornography. Hoaxes on social media became the main focus of several studies as well as the amount of access to pornography and game addiction [44]. With the type of internet usage that was mobile-addicted, Triastuti [39] explained that the frequency of internet usage through smartphones was more dominant than other digital devices. One study from Gayatri, et al. [37] revealed that it is easy for everyone to obtain pornographic content and engage in cyberbullying.

Readiness in using technology could be assessed on the users' age. Using the framework from Prensky [45], two groups were examined, namely digital natives and digital immigrants, which showed differences in technical and cognitive competition. Rahmawati, et al. [41] conducted a qualitative study on village principals in five cities across different provinces. They concluded that digital immigrants dominated the principals. Accordingly, they felt a lack of experience in using the internet. They were also helpless to counter the rush of misinformation and disinformation that circulates on social media. Kurniawati, Maolida, and Anjaniputra [46] examined teacher's readiness to use digital learning tools. They found that the digital native's teachers were unprepared to integrate instructional media and teaching practices. Conversely, digital immigrant teachers had increased their digital literacy, especially in utilizing digital tools to support their pedagogical abilities.

\subsection{Digital citizenship competence}

To understand the concept of digital citizenship applied in Indonesia, this study identified some conceptual frameworks that guided each research. During this process, there was one most-employed framework, the nine elements of digital citizenship from Ribble [20]. However, other studies also showed that digital citizenship is not limited to individual capability and represented social-political movements.

Researchers often used the framework of Ribble to guide the process of finding data. From all included articles, nine elements of digital citizenship were applied in five articles to frame digital citizenship competencies. Ribble [20] promoted digital citizenship as "norms of appropriate and responsible behavior concerning technology use," which consists of digital access, digital etiquette, digital literacy, digital communication, digital commerce, digital law, digital rights and responsibilities, digital security, digital health, and welfare. In several studies that used Ribble's work, digital literacy was an interesting dominant element to be observed [43], [47]. 
Armawi and Wahidin [44] conducted a study to explore the implementation of digital citizenship in school and the impact on student resilience. They discovered that the concepts of digital access, digital literacy, and digital commerce became the focus of strengthening digital citizenship to students in two senior high schools in Semarang, Central Java. Suryati and Harmanto [48] studied a technology infrastructure improvement program developed by the city government of Surabaya, Indonesia. They found digital access as a catalyst to increase digital citizenship to the residents. Accordingly, improving internet access and training to the community would enhance digital literacy, digital ethics, and digital commerce.

Internet users had the responsibility to evaluate the information that they obtained. Pradana [47] conducted a study using a qualitative approach and revealed that digital literacy aspects are essential to help internet users identify information rationally. Digital literacy was the first foundation to become an internetresponsible citizen. Benaziria [43] recommended digital literacy as a crucial component in the development of digital citizenship. Digital literacy was intended to show personal credibility and use digital media and the internet safely, responsibly, and ethically.

With the breadth of access and opportunities involved in various issues and policies, digital citizens used forums and digital media as channels to express ideas, opinions, and criticism to the government. Yue, Nekmat, and Beta [49] explored social movement patterns in women's groups in Singapore and Indonesia. They uncovered that Indonesian women used social media to collectively mobilize groups and entrepreneurial networks within conservative societies. Even though Indonesian women are shaped by gender and religion, some hashtag activist movements showed a certain momentum in political involvement. A study by Fauzanafi [50] was conducted to investigate digital citizenship as an alternative form of a citizen against political dynasties and corruption. Through this study, Fauzanafi said that digital citizenship as a new citizenship framework presented opportunities for developing rational and participatory citizenship.

In addition to the forms of public issues, the e-participation led to social movements and education. Nurdiyanti and Suryadi [51] conducted a case study on the philanthropic group in Bandung, West Java. They illustrated that the digital-based movement is the actualization of wise digital users that combined knowledge, attitudes, and skills in the online realm. By comparing the two schools in the UK and Indonesia [52] conducted a study to find that technology advancement could lead to stakeholder involvement. Instead of the complexity of this involvement and the school system, non-technological factors are needed.

Most studies address student competence, but some scholars emphasize the importance of developing digital citizenship for teachers. For example, several studies focus on developing ICT capability enhancement to teachers [53]-[55], and the use of a Learning Management System (LMS) or e-learning [56]. Based on the National Education Standards, it just mentioned providing equipment and infrastructure, including the learning resources needed to support online learning [57]. Furthermore, within the four competencies of professional teachers, none document explicitly informed the preparation of digital citizenship in the teacher education curriculum. Though, except for technical skills, teachers require to gain capabilities to solve non-cognitive problems in the use of technology. They are challenged to ensure that their students have the skills and attitudes adequately to use technology appropriately. Regarding social problems in using technology, teachers' abilities to use technology personally must be accompanied by the mastery of digital citizenship. As a digital citizen, Curran stresses that pre-service teachers should be committed to making solutions to various problems from local to global levels in the online community while the provision of digital competencies to them will open up opportunities to participate in civil discourse [58]. Consequently, pre-service teachers institutions should intend to provide a learning program to develop their digital citizenship competence [59].

\subsection{Educational policies}

The impact of technology occurred in all aspects of human beings, including encouraging educational reform in the 21 st-century. The teacher's role and readiness to apply technology in the curriculum were significant to optimize learning outcomes. Furthermore, this study noted that such educational programs for citizens initiated the focus of digital citizenship discourses in Indonesia.

The Indonesian teacher readiness in facing the digital era calls for attention. Mahdum, Hadriana, and Safriyanti [60] conducted a survey of teachers in rural areas to describe their perception and motivation to use digital tools for learning practices. The data findings showed that teachers have good perceptions and motivation in implementing technology-based learning. However, they dealt with constraints of lack of access and training. Previous studies [61], [62] highlighted that the use of ICT tools in teaching practice gave rise to meaningful learning and helped them in preparing the teaching process. Senjaya, et al. [38] also conducted a study to search the ICT awareness of high school students. Students showed that they were familiar and trained in using digital technology without the advanced teaching method from analyzing internet use patterns. Hence, teachers and school principals must prepare curricular programs to optimize student readiness.

Digital citizenship discourse was frequently discovered in a curricular program related to moral education, namely civic education. A quantitative study by Dewi and Budimansyah [63] aimed to examine 
civic education learning's impact on student's civic literacy. The results showed that civic education with meaningful learning had succeeded in increasing student's digital literacy. Komalasari and Anggraini [64] conducted a study to determine how teachers perceive digital citizenship and optimize civic education in developing digital citizenship. A survey method was used to obtain data from 174 teachers in West Bandung, West Java. This study revealed that teachers understand, apprehend, and aware of the concept of digital citizenship and its role in preparing students to become good digital users. This study suggested several strategies in civic education related to digital citizenship, such as living value-based education, blended learning, and self-regulated.

\subsection{Discussion}

This study is directed to answer the research question, "How does the current literature inform us of digital citizenship in Indonesia?" Content analysis of the included articles based on the PRISMA systematical review protocol emerged the following main findings: i) The development of digital citizenship in Indonesia is challenged by the issue of inappropriate use of technology; ii) Digital literacy, digital ethics, digital access, and digital participation are the main attributes of digital citizenship; and iii) Educational settings take a large proportion of the digital citizenship discourse with several considerations for incorporating ICT tools into learning activities.

All included articles refer to similar problem statements: improper behavior, lack of responsibility, and insecurity. When internet penetration makes the number of users increase exponentially, internet use impacts various social issues, such as fake news, hate speech, game addiction, cyberbullying, and pornography. Several studies [37]-[39] revealed patterns of use of internet users in Indonesia that are mobile-addicted, and the misuse of digital technology is not limited to certain age groups.

The characteristics of internet users in Indonesia are grouped into digital natives and digital immigrants. Some researchers assumed that digital natives have a higher readiness to adopt technology than the digital immigrant group [39], [42]. One study proved that the assumption is correct [41], while another study found contradictory findings [46].

Although the nine elements of digital citizenship developed by Ribble are widely adopted, researchers revealed that the problem of inappropriate use of technology is caused by low digital literacy [43], [46], [47]. Digital literacy becomes a vital element of digital citizenship. Furthermore, the lack of digital infrastructure should be addressed [44], [48]. Another study examined the curricular program to significantly increase digital literacy [63]. Previous researchers [50], [52], [65] also revealed that political participation in digital media is a manifestation of a good digital user, including efforts to mobilize voluntary movements [51].

Most studies on digital citizenship are conducted in educational settings. Researchers reported the integration of ICT into learning activities to promote meaningful learning [61], [62]. One study found that levels of perception and motivation are high. They believe in the incorporation of their learning preparation with ICT tools. Mostly, digital citizenship is attracting the attention of scholars to enhance the role of civic education by formalizing it into the curriculum [39], [43], [44], [63], [64].

In this respect, this study illustrated that the development of digital citizenship research could be explored for the proliferation of this concept into educational practice. The aforementioned findings provide a brief direction to begin reducing barriers in cultivating ethical and responsible behavior in the use of digital tools, such as equal distribution of internet access as initial rights, according to Ribble's framework, towards mastering other competencies. Furthermore, scholars need to examine the possibility that digital citizenship with all subscales with variables that potentially affected such as demographic [66], [67], internet self-efficacy, and internet usage frequency [68].

\subsection{Limitations}

Several criteria limit this systematic review. Consequently, some influential studies might be excluded. This study focused on the literature published in the past five years. This study believed that the topic of digital citizenship has developed before that period and growth continuously. The included criteria cannot cover all fields since most of the literature found was from the education field. Additionally, conference articles might bring several accountability conflicts, without eliminating the wealth of the empirical data displayed. This review excluded studies from dissertations and books because the peer review process is not as rigorous as a research journal.

\subsection{Implications for practice}

Studies on digital citizenship trends in Indonesia indicated that the problem of misuse of technology brings on social problems. Some researchers discovered several factors, such as the digital divide and unpreparedness of citizens in digital citizenship. This study illustrates the encouragement of the government and interest groups to implement strategic policies for improving student's competencies. Accordingly, the 
government needs to make policies to reduce the lack of digital access as the first step to eliminate the limits of fostering digital citizenship competence among Indonesian citizens.

\subsection{Recommendation for future research}

With these limitations of the study, future research needs to deeply consider the development of digital citizenship and the readiness to use technology. It is also imperative to search for suitable forms of measurement and structural modeling of digital citizenship in Indonesia. Moreover, since the included articles mostly come from the education field, researchers need to consider covering broader fields of study, such as engineering, computer science, economics, and psychology. Methodologically, the process of searching for literature depends on the features that exist in each database. As an example, Google Scholars almost summarizes every finding in other databases. Consequently, another future direction needs to use established databases, such as Web of Science (WoS) and The Education Resources Information Center (ERIC). Finally, this study recommends researchers pay attention to investigate and explore strategies for developing digital citizenship for teacher candidates. Noticeably, no single study attempts to fill the gap and contribute to teacher development by integrating digital citizenship into teacher institutions. As an example, it is necessary to improve the pedagogical skills among teachers in terms of using the digital platform as the learning media for their future class.

\section{CONCLUSION}

This systematic literature review has highlighted the challenges of digital citizenship development. Within the context of developing countries, such as Indonesia, providing empirical studies to support educational policies becomes principal to clarify how the concept has been developed and used. Based on the results, this study identified that digital citizenship consisted of several features, including digital literacy, digital ethics, digital access, and digital participation. Most scholars stated the misuse of technology and digital abuse due to digital inequality. Furthermore, this study recommends future research directions to explore integrating digital citizenship in educational practice.

\section{ACKNOWLEDGEMENTS}

The authors especially acknowledge, with gratitude, insightful written feedback on earlier drafts from Navila Roslidah and M. Luthfi Hidayat.

\section{REFERENCES}

[1] Asosiasi Penyelenggara Jasa Internet Indonesia (APJII), "Results of the 2018 Indonesian internet user behavior and penetration survey," (in Indonesia), 2018. [Online]. Available: https://apjii.or.id/content/read/39/410/Hasil-SurveiPenetrasi-dan-Perilaku-Pengguna-Internet-Indonesia-2018.

[2] R. W. Saputra, "A survey of cyber crime in Indonesia," in 2016 International Conference on ICT For Smart Society (ICISS), 2016, pp. 1-5, doi: 10.1109/ictss.2016.7792846.

[3] T. Paterson, "Indonesian cyberspace expansion : a double-edged sword Indonesian cyberspace expansion : a doubleedged sword," J. Cyber Policy, vol. 4, no. 2, pp. 216-234, 2019, doi: 10.1080/23738871.2019.1627476.

[4] F. Sulistyo and N. Manap, "Pornography and Sexual Crimes towards Children in Indonesia: A Judicial Approach," Brawijaya Law J., vol. 5, no. 2, pp. 261-270, 2018, doi: 10.21776/ub.blj.2018.005.02.09.

[5] T. S. Adiningrum, "Reviewing Plagiarism: An Input for Indonesian Higher Education," J. Acad. Ethics, vol. 13, no. 1, pp. 107-120, 2015, doi: 10.1007/s10805-015-9226-6.

[6] A. Santoso and F. R. Cahaya, "Factors influencing plagiarism by accounting lecturers," Account. Educ., vol. 28, no. 4, pp. 401-425, 2019, doi: 10.1080/09639284.2018.1523736.

[7] S. Alim, "Cyberbullying in the world of teenagers and social media: A literature review," Int. J. Cyber Behav. Psychol. Learn., vol. 6, no. 2, pp. 68-95, 2016, doi: 10.4018/IJCBPL.2016040105.

[8] T. Safaria, "Prevalence and Impact of Cyberbullying in a Sample of Indonesian Junior High School Students," TOJET Turkish Online J. Educ. Technol., vol. 15, no. 1, pp. 82-91, 2016.

[9] T. Safaria, F. Tentama, and H. Suyono, "Cyberbully, Cybervictim, and Forgiveness among Indonesian High School Students," TOJET Turkish Online J. Educ. Technol., vol. 15, no. 3, pp. 40-48, 2016.

[10] B. Rahardjo, "The state of cybersecurity in Indonesia," in E. Jurriens and R. Tapsell, Eds., Digital Indonesia: Connectivity and Divergence. Singapore: ISEAS Publishing, 2019, pp. 110-126.

[11] A. Almaarif and Qomariah, "Case Study on 'Prita Mulyasari' and 'Twin Hackers' in Indonesia," in 2014 International Conference on Information Technology Systems and Innovation, ICITSI 2014 - Proceedings, 2014, pp. 165-170, doi: 10.1109/ICITSI.2014.7048258.

[12] S. Pohan, "The right to be forgotten in public domain arrangements in social media in Indonesia," Int. J. Sci. Technol. Res., vol. 7, no. 8, pp. 200-203, 2018. 
[13] M. Harsasi, "The use of open educational resources in online learning: A study of students' perception," Turkish Online J. Distance Educ., vol. 16, no. 3, pp. 74-87, 2015.

[14] R. D. Kuntoro and S. Al-Hawamdeh, "E-learning in higher educational institutions in Indonesia," J. Inf. Knowl. Manag., vol. 2, no. 4, pp. 361-374, 2003, doi: 10.1142/S0219649203000553.

[15] P. Pannen, "Integrating technology in teaching and learning mathematics," Southeast Asian Mathematics Education Journal, vol. 5, no. 1, pp. 31-48, 2015, doi: 10.46517/seamej.v5i1.31.

[16] L. Sekarasih, "Restricting, Distracting, and Reasoning: Parental Mediation of Young Children's Use of Mobile Communication Technology in Indonesia," in S. S. Lim, Ed., Mobile Communication and the Family. Springer, Dordrecht, 2016, pp. 129-146.

[17] M. Choi, "A Concept Analysis of Digital Citizenship for Democratic Citizenship Education in the Internet Age," Theory Res. Soc. Educ., vol. 44, no. 4, pp. 565-607, 2016, doi: 10.1080/00933104.2016.1210549.

[18] A. Emejulu and C. McGregor, "Towards a radical digital citizenship in digital education," Crit. Stud. Educ., vol. 60, no. 1, pp. 131-147, 2019, doi: 10.1080/17508487.2016.1234494.

[19] B. Hui and R. Campbell, "Discrepancy between Learning and Practicing Digital Citizenship," J. Acad. Ethics, vol. 16, no. 2, pp. 117-131, 2018, doi: 10.1007/s10805-018-9302-9.

[20] M. Ribble, Digital citizenship in schools: Nine elements all students should know, 5th ed. United States: International Society for Technology in Education, 2015.

[21] Z. İbrahimoğlu, "Digital Citizenship and Education in Turkey: Experiences, the Present and the Future," in A. Peterson, G. Stahl, H. Soong, eds., The Palgrave Handbook of Citizenship and Education. Palgrave Macmillan, Cham, 2019, pp. 1-18, doi: 10.1007/978-3-319-67905-1_65-1.

[22] J. Fingal, "The 5 competencies of digital citizenship," International Society for Technology in Education (ISTE), 2019. [Online]. Available: https://www.iste.org/explore/digital-citizenship/5-competencies-digital-citizenship.

[23] M. Graham and W. H. Dutton, Society and the internet: How networks of information and communication are changing our lives. Oxford: Oxford University Press, 2019.

[24] S. J. Marshall, "Technology as a Catalyst for Change," in S. J. Marshall, Ed., Shaping the university of the future. Singapore: Springer, 2018, pp. 147-166.

[25] N. Miladi, "Social Media and Social Change," Dig. Middle East Stud., vol. 25, no. 1, pp. 36-51, 2016, doi: $10.1111 /$ dome.12082.

[26] A. Natarajan, "Human attitudes that prevent the advance of human progress and civilization," Cadmus, vol. 3, no. 3, pp. 154-163, 2017.

[27] D. Moher, et al., "Preferred reporting items for systematic review and meta-analysis protocols (PRISMA-P) 2015 statement," Syst. Rev., vol. 4, no. 1, pp. 1-9, 2015, doi: 10.1186/2046-4053-4-1.

[28] A. Liberati, et al., "The PRISMA statement for reporting systematic reviews and meta-analyses of studies that evaluate health care interventions: Explanation and elaboration," PLoS Med., vol. 6, no. 7, pp. 1-28, 2009, doi: 10.1371/journal.pmed.1000100.

[29] D. Moher, A. Liberati, J. Tetzlaff, and D. G. Altman, "Preferred Reporting Items for Systematic Reviews and MetaAnalyses: The PRISMA Statement (Reprinted from Annals of Internal Medicine)," Ann. Intern. Med., vol. 151, no. 4, pp. 264-270, 2009, doi: 10.1371/journal.pmed.1000097.

[30] M. Q. Patton, Qualitative Research \& Evaluation Methods: Integrating Theory and Practice, 4th ed. SAGE Publication, 2015.

[31] M. Petticrew and H. Roberts, Systematic reviews in the social sciences: A practical guide. John Wiley \& Sons, 2008.

[32] K. Ananiadou and M. Claro, "21st Century Skills and Competences for New Millennium Learners in OECD Countries," OECD Educ. Work. Pap., no. 41, OECD Publishing, Paris, 2009, doi: 10.1787/218525261154.

[33] S. K. W. Chu, R. B. Reynolds, N. J. Tavares, M. Notari, and C. W. Y. Lee, "Twenty-first century skills and global education roadmaps," in 21st Century Skills Development Through Inquiry-Based Learning: From Theory to Practice. Singapore: Springer, 2017, pp. 1-32.

[34] Battelle for Kids, "Frameworks \& Resources," 21st Century Learning a Network of Battelle for Kids, 2019. [Online]. Available: http://www.battelleforkids.org/networks/p21/frameworks-resources.

[35] C. Fadel, "21st Century Skills: How can you prepare students for the new Global Economy?" OECD/CERI, 2008. [Online]. Available: http://www.oecd.org/site/educeri21st/40756908.pdf.

[36] Battelle for Kids, "Framework for 21st Century Learning," 2019. [Online]. Available: http://static.battelleforkids.org/documents/p21/P21_Framework_Brief.pdf.

[37] G. Gayatri, et al., "Digital citizenship safety among children and adolescents in Indonesia," J. Penelit. dan Pengemb. Komun. dan Inform., vol. 6, no. 1, pp. 1-16, 2014.

[38] W. F. Senjaya, et al., "Information and communication technology awareness of Indonesian high school students," Glob. J. Eng. Educ., vol. 20, no. 3, pp. 217-223, 2018.

[39] R. Triastuti, "Teachers and technology: The perspective of digital citizenship," Jurnal Civics Media Kajian Kewarganegaraan, vol. 16, no. 1, pp. 22-28, 2019.

[40] C. Utama, Sajidan, J. Nurkamto, and Wiranto, "Digital literacy as a daily activity : Preferences of the main functions of technology," Univers. J. ofEducational Res., vol. 8, pp. 39-46, 2020, doi: 10.13189/ujer.2020.081706.

[41] D. Rahmawati, D. D. Kesa, P. Suciati, and A. Lusia, "Social challenges of spreading hoaxes by digital immigrants qualitative study on the implementation of digital citizenship and online safety in five cities," (in Indonesia), Seminar Nasional Teknologi Terapan Berbasis Kearifan Lokal, Vol. 2, No. 1, 2019, pp. 375-380. 
[42] D. I. Sari, T. Rejekiningsih, and M. Muchtarom, "Students' Digital Ethics Profile in the Era of Disruption: An Overview from the Internet Use at Risk in Surakarta City, Indonesia," Int. J. Interact. Mob. Technol., vol. 14, no. 3, pp. 82-94, 2020, doi: 10.3991/ijim.v14i03.12207.

[43] B. Benaziria, "Digital Literacy for Young Citizens in Civics Learning through the VCT Model," J. Pendidik. IlmuIlmu Sos., vol. 10, no. 1, pp. 11-20, 2018.

[44] A. Armawi and D. Wahidin, "Optimizing the role of internet in realizing digital citizenship and its implications for students' personal resilience," (in Indonesia), J. Civ. Media Kaji. Kewarganegaraan, vol. 17, no. 1, pp. 29-39, 2020.

[45] M. Prensky, "Digital Native and digital Immigrant," in On the horizon, vol. 9, no. 5, NCB University Press, 2001.

[46] N. Kurniawati, E. H. Maolida, and A. G. Anjaniputra, "The praxis of digital literacy in the EFL classroom : Digitalimmigrant vs digital-native teacher," Indones. J. Appl. Linguist., vol. 8, no. 1, pp. 28-37, 2018, doi: 10.17509/ijal.v8i1.11459.

[47] Y. Pradana, "Attribution of digital citizenship in digital literacy," (in Indonesia), Untirta Civ. Educ. J., vol. 3, no. 2, pp. 168-182, 2018, doi: 10.30870/ucej.v3i2.4524.

[48] L. Suryati and Harmanto, "Strategy of the technology and internet learning center (broadband learning center) in developing digital citizenship in the Surabaya city community," (in Indonesia), Kaji. Moral dan Kewarganegaraan, vol. 3, no. 3, pp. 956-970, 2018.

[49] A. Yue, E. Nekmat, and A. R. Beta, "Digital literacy through digital citizenship: Online civic participation and public opinion evaluation of youth minorities in Southeast Asia," Media Commun., vol. 7, no. 2, pp. 100-114, 2019, doi: 10.17645/mac.v7i2.1899.

[50] M. Z. Fauzanafi, "Searching for digital citizenship: Fighting corruption in Banten, Indonesia," Austrian J. SouthEast Asian Stud., vol. 9, no. 2, pp. 289-294, 2016, doi: 10.14764/10.ASEAS-2016.2-7.

[51] A. Nurdiyanti and K. Suryadi, "Digital Philanthropy in Indonesia: Strengthening Civic Virtue for Digital Citizens," in 1st International Conference on Progressive Civil Society (IConProCS 2019), vol. 317, 2019, pp. 139-143.

[52] M. Yusuf, C. Adams, and K. Dingley, "Digital citizen participation within schools in the United Kingdom and Indonesia: An Actor-Network Theory (ANT) perspective," Information, vol. 7, no. 4, pp. 1-27, 2016, doi: 10.3390/info7040069.

[53] Z. H. Putra, G. Witri, and T. Yulita, "Development of powerpoint-based learning media in integrated thematic instruction of elementary school," Int. J. Sci. Technol. Res., vol. 8, no. 10, pp. 697-702, 2019.

[54] P. I. Djiwandono, "How language teachers perceive information and communication technology," Indones. J. Appl. Linguist., vol. 8, no. 3, pp. 608-616, 2019, doi: 10.17509/ijal.v8i3.15260.

[55] A. Habibi, R. A. Razak, F. D. Yusop, and A. Mukminin, "Preparing future EFL teachers for effective technology integration: What do teacher educators say?" Asian EFL J., vol. 21, no. 2, pp. 9-30, 2019.

[56] B. Badaruddin, N. Noni, and B. Jabu, "The potential of ICT in blended learning model toward education 4.0 need analysis-based learning design for ELT," Asian EFL J., vol. 24, no. 4, pp. 128-142, 2019.

[57] F. Jalal, M. Samani, M. C. Chang, R. Stevenson, A. R. Bagatz, and S. D. Negara, Teacher certification in Indonesia: A strategy for teacher quality improvement. Indonesian Ministry of National Education and World Bank, 2009.

[58] M. Curran, "iCitizen: Are you a socially responsible digital citizen," Paper presented at the International Society for Technology Education Annual Conference, San Antonio, TX, 2012.

[59] M. Choi, D. Cristol, and B. Gimbert, "Teachers as digital citizens: The influence of individual backgrounds, internet use and psychological characteristics on teachers' levels of digital citizenship," Comput. Educ., vol. 121, pp. 143-161, 2018, doi: 10.1016/j.compedu.2018.03.005.

[60] M. Mahdum, H. Hadriana, and M. Safriyanti, "Exploring teacher perceptions and motivations to ICT use in learning activities in Indonesia," J. Inf. Technol. Educ. Res., vol. 18, pp. 293-317, 2019, doi: 10.28945/4366.

[61] A. Muslem, Y. Q. Yusuf, and R. Juliana, "Perceptions and barriers to ICT use among english teachers in Indonesia," Teach. English with Technol., vol. 18, no. 1, pp. 3-23, 2018.

[62] T. M. Silviyanti and Y. Q. Yusuf, "EFL teachers' perceptions on using ICT in their teaching: To use or to reject?" Teach. English with Technol., vol. 15, no. 4, pp. 29-43, 2015.

[63] D. A. Dewi and D. Budimansyah, "The Effect of Civics Learning Implementation on Improving Civic Literacy in Digital Citizenship Era," in 2nd Annual Civic Education Conference (ACEC), 2020, vol. 418, pp. 77-81.

[64] K. Komalasari and D. N. Anggraini, "Civic Education for Development of Digital Citizenship in the Era of Industrial Revolution 4.0," in 2nd Annual Civic Education Conference (ACEC), 2020, vol. 418, pp. 151-154.

[65] A. Yue, E. Nekmat, and A. R. Beta, "Digital literacy through digital citizenship: Online civic participation and public opinion evaluation of youth minorities in Southeast Asia," Media Commun., vol. 7, no. 2, pp. 100-114, 2019, doi: 10.17645/mac.v7i2.1899.

[66] R. Ata and K. Yildirim, "Turkish pre-service teachers' perceptions of digital citizenship in education programs," J. Inf. Technol. Educ. Res., vol. 18, pp. 419-436, 2019.

[67] F. G. A. Trapero, J. C. V. Parra, and M. D. J. G. Martínez, "Digital Citizenship Approach and Teacher Profile," Educ. Knowl. Soc., vol. 21, pp. 1-11, 2020, doi: 10.14201/eks.22735.

[68] M. Choi, D. Cristol, and B. Gimbert, "Teachers as digital citizens: The influence of individual backgrounds, internet use and psychological characteristics on teachers' levels of digital citizenship," Comput. Educ., vol. 121, pp. 143-161, 2018, doi: 10.1016/j.compedu.2018.03.005. 